\title{
Commentary
}

\section{A Question of Transformation}

\section{The Synovial Fibroblast in Rheumatoid Arthritis}

\author{
Laurie S. Davis \\ From the Department of Internal Medicine, University of Texas \\ Southwestern Medical Center, Dallas, Texas
}

Rheumatoid arthritis (RA) is a chronic, systemic, autoimmune disease with an unknown etiology. Both genetic and environmental factors contribute to disease susceptibility and the prevalence of RA is greater in women than in men. RA is characterized by initial vasculitis of the joint, followed by edema, infiltration of immune and inflammatory cells into the synovium, hyperplasia of the synovial lining, formation of lymph follicles, and development of the pannus. There is progressive cartilage destruction and finally erosion of the underlying bone. Current evidence suggests that fibroblast-like synoviocytes are one of the principle cells involved in pannus formation and cartilage degradation. Fibroblast-like synoviocytes in the rheumatoid synovium have characteristics similar to transformed cells and have been shown to proliferate in an anchorage-independent manner, lack contact inhibition, and express oncogenes and cell cycle proteins indicative of transformation. In vivo models have demonstrated that fibroblast-like synoviocytes can autonomously mediate cartilage destruction. In the article by Seemayer and colleagues in this issue of The American Journal of Pathology a direct comparison is made between SV40-transformed rheumatoid fibroblast-like synoviocytes and untransformed cells. ${ }^{1}$ These experiments challenge the paradigm that rheumatoid synoviocytes are characterized by both aggressive growth and invasiveness. Of interest, the results demonstrate that fibroblast-like synoviocytes, capable of forming the pannus and invading cartilage, have an activated phenotype and secrete high levels of matrix-degrading enzymes, but have a limited capacity to proliferate. Conversely, SV40transformed cells rapidly proliferate, secrete lower levels of matrix-degrading enzymes, display different levels of adhesion molecules, and demonstrate limited cartilage invasion. Thus these studies reveal an important dissociation between synoviocyte proliferation and invasiveness. This article reviews the tumor-like characteristics of fibroblast-like synoviocytes and discusses the contribution of synoviocytes to the pathogenesis of RA.

\section{Origin}

Fibroblast-like synoviocytes, once known as type B lining cells, are mesenchyme-derived cells. ${ }^{2,3}$ Fibroblast-like synoviocytes and macrophage-like (type A) cells form a thin lining of synovial tissue surrounding the fibrous capsule of the joint. The lining cells secrete synovial fluid that forms a protective film that provides lubrication and nutrients to the cartilage. The synovial lining thickens in rheumatoid disease. The synovium becomes hypertrophic and is composed of fibroblast-like synoviocytes of the lining layer or intimal fibroblasts and the subintimal fibroblasts. In RA, intimal fibroblast-like synoviocytes express a more activated phenotype and function than those in the subintimal tissue. Currently it is unknown whether intimal and subintimal fibroblasts represent independent lineages, however, it is more likely that the local milieu influences function. No difference is noted in cells derived from different layers when placed in culture. Fibroblast-like synoviocytes share a common progenitor with bone marrow stromal cells and display a similar gene expression profile. Thus, similar to bone marrow stromal cells the fibroblast-like synoviocytes can play a supportive and modulatory role in influencing other cells found in the synovium. Normally, fibroblast-like synoviocytes have little contact with immune cells. In RA, however, fibroblast-like synoviocytes are stimulated by immune and inflammatory cells. Rheumatoid synoviocytes are characterized by proliferation, pannus formation, and secretion of factors that promote inflammation, neovascularization, and cartilage degradation.

\section{Proliferation versus Apoptosis}

Substantial interest has been focused on the question of whether synovial hyperplasia is the result of rapid growth of fibroblast-like synoviocytes or the result of defective

Accepted for publication February 20, 2003.

Address reprint requests to Laurie S. Davis, Ph.D., UT Southwestern Medical Center, Department of Internal Medicine, 5323 Harry Hines Blvd., Y8.206, Dallas, TX 75390-8884. E-mail: laurie.davis@utsouthwestern.edu. 
apoptotic death. Animal models have demonstrated a correlation between the unique immune physiology of the joint, synovial hyperplasia, and cartilage degradation. In these models, synovial hyperplasia and cartilage destruction rapidly develop and can often be observed within a month after immune challenge. ${ }^{4,5}$ Likewise, inflamed synovium and synovitis was observed 2 months after arthroscopic synovectomy of human rheumatoid knees indicating the capacity of the rheumatoid synovium to rapidly regenerate. ${ }^{6}$ In other studies, the presence of macrophages and B cells in the synovium was inversely correlated with clinical improvement after arthroscopic synovectomy indicating the role of leukocytes in perpetuating synovial hyperplasia and synovitis. ${ }^{7}$ These and other studies indicate that fibroblast-like synoviocytes have the potential to undergo rapid proliferation in vivo and that immune and inflammatory cells potentiate the response. A number of in vitro studies have reported variable results. Microscopic examination of a marker of proliferation, Ki67, demonstrates localized foci of proliferating fibroblast-like synoviocytes in the lining layer of synovium. In some cases synoviocytes appear to grow in a monoclonal or oligoclonal manner. ${ }^{8}$ Moreover, transcription factors, regulating cell cycle and proapoptotic molecules, such as c-myc, c-jun, c-fos, and nuclear factor $-\kappa \mathrm{B}$ as well as telomerase activity were increased in synoviocytes. $^{8}$ In tissue culture some reports indicate that rheumatoid fibroblast-like synoviocytes grow rapidly for multiple passages in the presence of growth factor, whereas others have found that these synoviocytes have a rather low proliferation rate and do not have a faster doubling time than cells from osteoarthritic synovium. ${ }^{9,10}$ Discrepancies in these studies might be the result of differences in the stage of synovial tissue used for isolation of synoviocytes, the type of synoviocytes, or culture conditions. ${ }^{11,12}$ Defective apoptosis is a second mechanism contributing to synovial hyperplasia. Whereas initial studies indicated increased levels of apoptosis in the rheumatoid synovium, recent investigations have demonstrated both in vivo and in vitro evidence of the resistance of synoviocytes to apoptosis. Highton and colleagues ${ }^{13}$ have shown that apoptotic cell death of fibroblasts was rarely observed in rheumatoid nodules and synovial membranes as opposed to the high rates of apoptosis associated with sarcoid granulomas. Fibroblast-like synoviocytes have been reported to express altered levels of apoptotic signaling molecules such as p16, SENTRIN, and PTEN. ${ }^{14-17}$ Moreover, fibroblast-like synoviocytes resist apoptotic signals delivered through both of the major death pathways, Fas and tumor necrosis factor (TNF)- $\alpha$ receptor. Adhesion molecules, such as CD44, up-regulate Fas expression on the surface of synoviocytes. ${ }^{18}$ However, ligation of Fas and TNF- $\alpha$ receptors is ineffective at inducing apoptosis in rheumatoid synoviocytes. In this regard, recent studies suggest that proinflammatory cytokines such as TNF- $\alpha$ might play a critical role in synoviocyte resistance to apoptosis. A potential mechanism of anti-TNF- $\alpha$ therapies might be to increase the susceptibility of synoviocytes to apoptosis. ${ }^{19}$ Thus, fibroblast-like synoviocytes resemble malignant cells in potentially high proliferative capacity and expression of dys- regulated intracellular molecules that can modulate cell cycle progression and apoptosis.

\section{Invasiveness}

The dysregulation of the transcription factors AP-1 and nuclear factor $-\kappa \mathrm{B}$, and the tumor suppressor gene, $p 53$, have been implicated in the aggressive proliferative and invasive functions of fibroblast-like synoviocytes. ${ }^{20-25}$ The tumor suppressor gene, p53, becomes activated at sites of chronic inflammation. The cell-cycle regulatory protein, p53, induces cell growth arrest allowing time for DNA repair mechanisms to occur. Alternatively if the damage is extensive, allows the cell to undergo apoptosis. In a subset of patients with longstanding or highly aggressive disease, fibroblast-like synoviocytes appear to make a transition from dependency on inflammatory mediators to autonomous progression. Increased reactive oxygen species and reactive nitrogen species are found in elevated levels in the rheumatoid synovium. ${ }^{25}$ The DNA damage caused by chronic exposure of cells to oxidizing and nitrating agents along with certain cytokines has been proposed as a major mechanism for the association of some chronic inflammatory conditions with cancers such as in the case of Helicobacter pylori infection and gastric cancer. The accumulation of p53 has been observed in fibroblast-like synoviocytes from rheumatoid patients but not patients with osteoarthritis. Thus chronic inflammation and resulting DNA damage might lead to mutations in crucial regulatory genes such as p53 and proapoptotic genes. Multiple mutations in p53 have been observed in a single joint, thereby making analysis difficult by single strand conformational polymorphism (SSCP) or other standard methods. ${ }^{23}$ However, recent data suggest that p53 mutations can be found in fibroblast-like synoviocytes of rheumatoid patients with longstanding erosive disease. Mutations in p53 result in a dominant-negative phenotype and can suppress normal gene function. In experiments inhibiting p53 in fibroblastlike synoviocytes, the resultant cells expressed many of the characteristics of rheumatoid fibroblast-like synoviocytes including anchorage-independent growth, invasiveness into cartilage, and impaired apoptosis. Therefore, it is possible that invasive fibroblasts, like the leading edge of invasive tumors have down-regulated proliferative signals and activated other signal transduction pathways to increase the rate of secretion and variety of matrix-degrading enzymes. This paradigm is reminiscent of cells such as stimulated lymphocytes, which temporarily arrest in the early $G_{1}$ phase of the cell cycle to perform effector functions.

\section{Soluble Mediators}

In response to cytokines, such as TNF- $\alpha$ and interleukin-1, produced by macrophages, fibroblast-like synoviocytes secrete matrix metalloproteinases (MMPs) and other matrix-degrading enzymes, such as aggrecanases (ADAMTS) and cathepsins. ${ }^{26,27}$ New information on these molecules is emerging at a rapid pace and sug- 
gests that these enzymes play an important role in many aspects of cancer metastasis. ${ }^{27}$ Similar to malignant cells, MMPs and cathepsins released from fibroblast-like synoviocytes can activate or inactivate cytokines and chemokines, release proapoptotic ligands from cell surfaces, and promote invasion of the cartilage. ${ }^{28-31}$ There are at least 24 MMPs known and each has a unique specificity for collagens, fibronectin, elastin, gelatin, and proteoglycans. Intimal or lining layer fibroblast-like synoviocytes and synoviocytes invading cartilage are the major producers of MMPs in the rheumatoid synovium. The extracellular matrix-degrading enzymes can be activated by growth factors and proto-oncogenes that are up-regulated at sites of cartilage invasion. MMP-1, -8 , and -13 were previously known as collagenase-1, -2 , and -3 . MMP-8 can be produced by neutrophils as well as fibroblasts. Fibroblasts also produce MMP-3, which degrades proteoglycans and collagen types I and II, and MMP-14 that not only participates in cartilage degradation, but also activates other MMPs. Cathepsin $L$ and cathepsin $K$ are potent collagen-degrading proteases that are produced in the rheumatoid synovium. Activated synoviocytes also produce ADAMTS-5 and ADAMTS-11 that degrade aggregan, the major proteoglycan found in cartilage. As mentioned previously, in late stages of rheumatoid disease, the evidence suggests that synoviocytes can autonomously degrade cartilage much like tumor cells degrade the extracellular matrix. Fibroblast-like synoviocytes can secrete a number of other soluble mediators, such as cytokines and chemokines in response to various stimuli. ${ }^{8}$ Rheumatoid synoviocytes attract leukocytes by expressing chemokines such as interleukin-8, MIP-1, and RANTES. Synoviocytes promote the growth of myeloid and lymphoid cells by the secretion of colonystimulating factors and produce autocrine growth factors such as platelet-derived growth factor. In response to hypoxic conditions that exist in some areas of the rheumatoid synovium, synoviocytes can produce angiogenic factors such as vascular endothelial growth factor and stromal cell-derived factor 1. Fibroblast-like synoviocytes can modulate immune function by the secretion of transforming growth factor $-\beta$, soluble TNF- $\alpha$ receptors, and interleukin-10 as well as extracellular matrix degradation by tissue inhibitors of metalloproteinases. Similar mechanisms exist in tumor cells that allow them to promote growth via influencing proliferation, adhesion, migration, angiogenesis, and apoptosis.

\section{RA and Cancer}

Despite evidence for transformation of fibroblast-like synoviocytes in patients with RA, cancer of the synovium is rare, with the most common form being transformation of cells composing the tendon sheaths. ${ }^{32}$ Therefore, the destructive nature of RA might potentially prevent transformation events in synoviocytes from evolving into malignant tumors. Nonetheless, some have characterized RA as "cancer of the joint" based on mortality rates for RA being similar to certain lymphomas and the localized hyperplasia and angiogenesis observed in the rheuma- toid synovium. ${ }^{8}$ In recent years an association has been drawn between RA and increased cancer risks. ${ }^{33,34}$ These include acute and chronic leukemia, multiple myeloma, and non-Hodgkin's lymphoma, overall representing an eightfold increased risk for hematological cancers whereas no apparent association exists with solid tumors. Patients with severe RA also have an increased risk for lymphoproliferative disorders, lung cancer, and melanoma. In cancer patients and in RA patients, there is an increased prevalence of specifically induced autoantibodies. $^{35,36}$ In cancer the autoantibodies recognize autoantigenic determinants of oncogenes or tumor suppressor genes. Previous work suggests a direct connection between the appearance of anti-p53 antibodies and subsequent detection of liver angiosarcoma and lung cancer. The appearance of these autoantibodies might also be attributable to the aging process and might not be related to cancer. Thus, the presence of an autoimmune response might be either predictive or contributive to the occurrence of specific tumors and hematological malignancies. Potential causes for the association include a genetic susceptibility resulting in subsequent oncogene activation, alteration of oncoproteins, immunodeficiency, or other defects that facilitate both autoimmunity and cancer.

\section{References}

1. Seemayer CA, Kuchen S, Kuenzler P, Rihoskova V, Rethage J, Aicher WK, Michel BA, Gay RE, Kyburz D, Neidhart M, Gay S: Cartilage destruction mediated by synovial fibroblasts does not depend on proliferation in rheumatoid arthritis. Am J Pathol 2003, 162:1549-1557

2. Edwards JCW: Fibroblast biology: development and differentiation of synovial fibroblasts in arthritis. Arthritis Res 2002, 2:344-347

3. Pap T, Muller-Ladner U, Gay RE, Gay S: Fibroblast biology: role of synovial fibroblasts in the pathogenesis of rheumatoid arthritis. Arthritis Res 2000, 2:361-367

4. Leung BP, Conacher M, Hunter D, Mclnnes IB, Liew FY, Brewer JM: A novel dendritic cell-induced model of erosive inflammatory arthritis: distinct roles for dendritic cells in T cell activation and induction of local inflammation. J Immunol 2002, 169:7071-7077

5. Mandik-Nayak L, Wipke BT, Shih FF, Unanue ER, Allen PM: Despite ubiquitous autoantigen expression, arthritogenic autoantibody response initiates in the local lymph node. Proc Natl Acad Sci USA 2002, 99:14368-14373

6. Ostergaard M, Ejbjerg B, Stoltenberg M, Gideon P, Volck B, Skov K, Jensen $\mathrm{CH}$, Lorenzen I: Quantitative magnetic resonance imaging as a marker of synovial membrane regeneration and recurrence of synovitis after arthroscopic knee joint synovectomy: a one year follow up study. Ann Rheum Dis 2001, 60:233-236

7. Tanaka N, Sakahashi H, Sato E, Ishii S: Immunohistological indication for arthroscopic synovectomy in rheumatoid knees: analysis of synovial samples obtained by needle arthroscopy. Clin Rheumatol 2002, 21:46-51

8. Jenkins JJ, Hardy KJ, McMurray RW: The pathogenesis of rheumatoid arthritis: a guide to therapy. Am J Med Sci 2002, 323:171-180

9. Aicher WK, Heer AH, Trabandt A, Bridges Jr SL, Schroeder Jr HW Stransky G, Gay RE, Eibel H, Peter HH, Slebenlist U, Gay S: Overexpression of zinc-finger transcription factor Z-225/Egr-1 in synoviocytes from rheumatoid arthritis patients. J Immunol 1994, 152:59405948

10. Nykanen P, Bergroth V, Raunio P, Nordstrom D, Konttinen YT: Phenotypic characterization of $3 \mathrm{H}$-thymidine incorporating cells in rheumatoid arthritis synovial membrane. Rheumatol Int 1986, 6:269-271

11. Masuda K, Masuda R, Neidhart M, Simmen BR, Michel BA, MullerLaden U, Gay RE, Gay S: Molecular profile of synovial fibroblasts in 
rheumatoid arthritis depends on the stage of proliferation. Arthritis Res 2002, 4:R8

12. Tanaka $\mathrm{Y}$, Nomi M, Fujii $\mathrm{K}$, Hubscher $\mathrm{S}$, Maruo A, Matsumoto $\mathrm{S}$, Awazu Y, Saito K, Eto S, Minami Y: Intercellular adhesion molecule 1 underlies the functional heterogeneity of synovial cells in patients with rheumatoid arthritis. Arthritis Rheum 2000, 43:2513-2522

13. Highton J, Hessian PA, Kean A, Chin M: Cell death by apoptosis is a feature of the rheumatoid nodule. Ann Rheum Dis 2003, 62:77-80

14. Taniguchi $\mathrm{K}$, Kohsaka $\mathrm{H}$, Inoue N, Terada $\mathrm{Y}$, Ito $\mathrm{H}$, Hirokawa $\mathrm{K}$, Miyasaka N: Induction of the p16INK4a senescence gene as a new therapeutic strategy for the treatment of rheumatoid arthritis. Nat Med 1999, 5:760-767

15. Pap T, Franz JK Hummel KM, Jeisy E, Gay RE, Gay S: Activation of synovial fibroblasts in rheumatoid arthritis: lack of expression of the tumor suppressor PTEN at sites of invasive growth and destruction. Arthritis Res 2000, 2:59-65

16. Di Cristofano A, Kotsi P, Peng YF, Cordon-Cardo C, Elkon KB, Pandolfi PP: Impaired Fas response and autoimmunity in Pten $+/$ - mice. Science 1999, 285:2122-2125

17. Franz JK, Pap T, Hummel KM, Nawrath M, Aicher WK, Shigeyama Y, Muller-Ladner U, Gay RE, Gay S: Expression of sentrin, a novel anti-apoptotic molecule at sites of synovial invasion in rheumatoid arthritis. Arthritis Rheum 2000, 43:599-607

18. Fujii K, Fujii $Y$, Hubscher S, Tanaka Y: CD44 is the physiological trigger of fas up-regulation on rheumatoid synovial cells. J Immunol 2001, 167:1198-1203

19. Ohshima S, Mima T, Sasai M, Nishioka K, Shimizu M, Murata N, Yoshikawa H, Nakanishi K, Suemura M, McCloskey RV, Kishimoto T, Saeki Y: Tumour necrosis factor alpha (TNF- $\alpha$ ) interferes with fasmediated apoptotic cell death on rheumatoid arthritis (RA) synovial cells: a possible mechanism of rheumatoid synovial hyperplasia and a clinical benefit of anti-TNF- $\alpha$ therapy for RA. Cytokine 2000, 12:281288

20. Asahara H, Fujisawa K, Kobata T, Hasunuma T, Maeda T, Asanuma M, Ogawa N, Inoue H, Sumida T Nishioka K: Direct evidence of high DNA binding activity of transcription factor AP-1 in rheumatoid arthritis synovium. Arthritis Rheum 1997, 40:912-918

21. Tak PP, Gerlag DM, Aupperle KR, van de Geest DA, Overbeek M, Bennett BL, Boyle DL, Manning AM, Firestein GS: Inhibitor of nuclear factor $\kappa \mathrm{B}$ kinase beta is a key regulator of synovial inflammation. Arthritis Rheum 2001, 44:1897-1907

22. Pap T, Aupperle KR, Gay S, Firestein GS, Gay RE: Invasiveness of synovial fibroblasts is regulated by p53 in the SCID mouse in vivo model of cartilage invasion. Arthritis Rheum 2001, 44:676-681

23. Yamanishi Y, Boyle DL, Rosengren S, Green DR, Zvaifler NJ, Firestein GS: Regional analysis of p53 mutations in rheumatoid arthritis synovium. Proc Natl Acad Sci USA 2002, 99:10025-10030

24. Yamanishi Y, Boyle DL, Pinkoski MJ, Mahboubi A, Lin T, Han Z,
Zvaifler NJ, Green DR, Firestein GS: Regulation of joint destruction and inflammation by p53 in collagen-induced arthritis. Am J Pathol 2002, 160:123-130

25. Tak PP, Smeets TJM, Boyle DL, Kraan MC, Shi Y, Zhuang S, Zvaifler $\mathrm{NJ}$, Breedveld F, Firestein GS: p53 overexpression in synovial tissue from patients with early and longstanding rheumatoid arthritis compared with reactive arthritis and osteoarthritis. Arthritis Rheum 1999, 42:948-953

26. Scott BB, Weisbrot LM, Greenwood JD, Bogoch ER, Paige CJ, Keystone EC: Rheumatoid arthritis synovial fibroblast and U937 macrophage/monocyte cell line interaction in cartilage degradation. Arthritis Rheum 1997, 40:490-498

27. Egeblad M, Werb Z: New functions for the matrix metalloproteinases in cancer progression. Nat Rev Cancer 2002, 2:161-174

28. Perlman H, Bradley K, Liu H, Cole S, Shamiyeh E, Smith RC, Walsh K, Fiore S, Koch AE, Firestein GS, Haines III GK, Pope RM: IL-6 and matrix metalloproteinase- 1 are regulated by the cyclin-dependent kinase inhibitor p21 in synovial fibroblasts. J Immunol 2003, 170:838845

29. Tolboom TCA, Pieterman E, van der Laan WH, Toes REM, Huidekoper AL, Nelissen RGHH, Breedveld FC, Huizinga TWJ: Invasive properties of fibroblast-like synoviocytes: correlation with growth characteristics and expression of MMP-1, MMP-3, and MMP-10. Ann Rheum Dis 2002, 61:975-980

30. Van der Laan WH, Quax PHA, Seemayer CA, Huisman LGM, Pieterman EJ, Grimbergen JM, Verheijen JH, Breedveld FC, Gay RE, Gay S, Huizinga TWJ, Pap T: Cartilage degradation and invasion by rheumatoid synovial fibroblasts is inhibited by gene transfer of TIMP-1 and TIMP-3. Gene Therapy 2003, 10:234-242

31. Smeets TJM, Kraan MC, Galjaard S, Youssef PP, Smith MD, Tak PP Analysis of the cell infiltrate and expression of matrix metalloproteinases and granzyme B in paired synovial biopsy specimens from the cartilage-pannus junction in patients with RA. Ann Rheum Dis 2001, 60:561-565

32. Nilsson M, Hoglund M, Panagopoulos I, Sciot R, Dal Cin P, DebiecRychter M, Mertens F, Mandahl N: Molecular cytogenetic mapping of recurrent chromosomal breakpoints in tenosyovial giant cell tumors. Virchows Arch 2002, 441:475-480

33. Prior P: Cancer and rheumatoid arthritis: epidemologic considerations. Am J Med 1985, 78(Suppl. 1A):15-21

34. Mellemkjaer L, Linet MS, Gridley G, Frisch M, Moller H, Olsen JH Rheumatoid arthritis and cancer risk. Eur J Cancer 1996, 32A:17531757

35. Crawford L, Pim D, Bulbrook R: Detection of autoantibodies against the cellular protein p53 in sera from patients with breast cancer. Int $\mathrm{J}$ Cancer 1982, 30:403-408

36. Tan E: Autoantibodies in pathology and cell biology. Cell 1991, 67: 841-842 